\title{
Will Procreation Ever Be The Same After COVID-19?
}

\author{
Gautam Allahbadia ${ }^{1,2}$
}

Received: 2 August 2021 / Accepted: 2 August 2021 / Published online: 30 August 2021

(c) Federation of Obstetric \& Gynecological Societies of India 2021

\begin{abstract}
Medically assisted procreation will never be the same again after this China Virus epidemic. With billions of lives being affected by this damaging global pandemic, medically assisted procreation services were not left unharmed with far-reaching consequences. New challenges are now emerging concerning COVID-19, such as associated reproductive implications and the consequences of assisted and natural procreation in the presence of acute SARS-CoV-2 infection and delayed consequences after patient recovery. There is a hypothesis that testicular damage and subsequent infertility may result following COVID-19 infection and the possibility of sexual transmission, as SARS-CoV-2 has been identified in the semen of infected patients. Vaccine hesitancy in young women planning pregnancies has been heightened because of the spread of misinformation on social media stating that COVID-19 vaccines will cause sterility in women. Reassuring data from accidental pregnancies that have occurred in the clinical trials of approved COVID-19 vaccines indicate that vaccination does not harm fertility or increase the rate of miscarriage. Scientists have quickly related to good tissue practices in vitro fertilization and a rethink is on about encouraging biopsies and focusing on safe vitrification protocols keeping in mind that ova, sperm, and embryos could be possible vectors for disease transmission with the limited research on the SARS-CoV-2 virus. Going ahead with segmented IVF without delay, freezing the generated embryos and pushing back the embryo transfer after the pandemic appears to be the best strategy at present. An international group of researchers have proposed a prognostic stratification of more vulnerable infertility cases in order to plan a progressive restart of worldwide fertility treatments.
\end{abstract}

Procreation the act or process of begetting offspring: The techniques of medically assisted procreation are constantly progressing. Procreation perpetuates the species-hippos give birth to hippos, not humans : dictionary.com/browse/procreation

\section{Introduction}

The current outbreak of the novel 2019 coronavirus disease (COVID-19) started in China in December 2019 and has since spread to several other countries. The pandemic caused by the COVID-19 virus also called the China virus by the

Gautam Allahbadia is a Consultant Reproductive Endocrinology \& IVF at Rotunda-The Center For Human Reproduction, Parel, Mumbai, India and MMC IVF, Dubai, UAE.

Gautam Allahbadia

ivfwaladoc@gmail.com

1 Rotunda-The Center For Human Reproduction, Parel, Mumbai, India

2 MMC IVF, Dubai, UAE previous American President has wreaked havoc on the socio-economic fabric of the world population. With billions of lives affected by this damaging global pandemic, medically assisted procreation services were not left unharmed with far reaching consequences. Sexual transmissibility of SARS-CoV-2 virus, its effect on male and female fertility, pregnancy, a potential teratogenic side effect, and safe gamete handling in IVF labs are realistic concerns among IVF physicians which has slowed down all ART services globally including IUI, IVF/ICSI and even routine registration of new patients. The general populace has postponed normal procreation, and sub-fertile couples are pushing back their plans to take treatments because of the media generated fear of procreation today. Clear evidence regarding the causeand-effect relationship of the China virus infection and its impact on human procreation is yet to come in.

As of July 27, 2021, 195,705,870 confirmed cases and $4,188,862$ deaths due to the novel coronavirus disease 2019 (COVID-19)-which is caused by the new, severe acute respiratory syndrome coronavirus 2 (SARS-CoV-2)-have been reported worldwide [1]. Although COVID-19 was first identified as a respiratory ailment, it is now considered a systemic disease, as it may affect different organs [2]. 
New challenges are now emerging concerning COVID-19, such as associated reproductive implications and the consequences of assisted and natural procreation in the presence of acute SARS-CoV-2 infection and delayed consequences after patient recovery [3].

Two recent 2021 studies show the COVID-19 vaccine has no impact on male or female reproductive potential. University of Miami's study [4] was published as a Letter to the Editor on June 17, 2021, in the Journal of the American Medical Association which shows the COVID-19 vaccine does not affect sperm count. In addition, Fertility and Sterility published a study in July 2021 [5] that concluded the COVID-19 vaccine does not result in female sterility. Both studies should reassure the public about the safety of the mRNA American technology COVID-19 vaccine $[4,5]$. ASRM maintains its position and guidelines that vaccination is the best way to avoid getting or transferring the COVID19 coronavirus and should not dissuade anyone from building or adding to their family [6].

Vaccine hesitancy in young women planning pregnancies has been heightened as a result of the spread of misinformation on social media stating that COVID-19 vaccines will cause sterility in women [7]. Meanwhile, those offered the vaccine during pregnancy must decide whether they will accept, even though pregnant people were excluded from the vaccine clinical trials. Data on accidental pregnancies that occurred during the trials and, increasingly, outcomes in pregnant people who receive the vaccine can help these groups to make informed decisions. Reassuring data from accidental pregnancies that have occurred in the clinical trials of approved COVID-19 vaccines indicate that vaccination does not harm fertility or increase the rate of miscarriage [8]. All said and done, evidence-based medicine will give us concrete long-term clinical side-effects if any only a few years down the line.

\section{Discussion}

On December 1, 2020, the former head of respiratory research of Pfizer filed a plaint to the European Medicine Agency calling for the immediate suspension of all SARSCoV-2 vaccine studies [9]. One of the concerns filed in the plaint was "infertility of indefinite duration in vaccinated women." However, the theoretical danger was not because of the vaccine per se, but from the subsequent production of antibodies against the SARS-CoV-2 virus spike protein and their cross-reaction with syncytin- 1 . Why this would be different than the antibodies produced from natural infection was never explained till date. Several published reports claimed that the purported similarity between syncytin-1 and the SARS-CoV-2 spike protein may induce immune cross-reactivity resulting in female sterility $[10,11]$. Morris used frozen embryo transfer as a model for comparing the implantation rates between SARS-CoV-2 vaccine seropositive, infection seropositive, and seronegative women [5]. No difference was found in serum beta hCG documented implantation rates or sustained implantation rates between the three groups. The author concluded that reports claiming that COVID-19 vaccines or illness cause female sterility are unfounded [5].

\section{Male Infertility}

The severe acute respiratory syndrome coronavirus 2 (SARS-CoV-2) pandemic has led to various theories of functional alteration of different organ systems. The direct influence of this virus on the male urogenital organs was published from China in 2020 as postmortem studies [12]. Precise mechanisms of testicular damage are still unclear, but it seems that high temperature resulting from persistent fever and triggering a secondary autoimmune response leading to an autoimmune orchitis are the most likely involved mechanisms. However, some hypotheses can already be made, especially in the andrological field, because of the biological similarity of the SARS-CoV and SARS-CoV-2. Both SARS-CoV and SARS-CoV-2 use the 'Angiotensin Converting Enzyme-2' (ACE2) as a receptor to enter human cells. It was found that ACE2, angiotensin and its MAS receptors are present in the lungs and also in the testes, concentrated in Leydig and Sertoli cells [13-17]. The first theory is that the virus can enter the testis and lead to alterations in testicular functionality. The second theory is that the binding of the virus to the ACE2 receptor can cause an excess of ACE2 and give rise to a typical inflammatory response. The inflammatory cells could interfere with the function of Leydig and Sertoli cells. Both these theories are being currently evaluated to confirm and possibly monitor fertility in patients post-COVID-19 [18].

\section{Female Infertility}

An early report in 2020 suggested female sex hormone levels and ovarian reserve did not change significantly postCOVID-19 infection in women of reproductive age [19]. Nearly one-fifth of patients exhibited a menstrual volume decrease or cycle prolongation. The menstruation changes of these patients might be a consequence of transient sex hormone changes caused by suppression of ovarian function that quickly resume after recovery [19].

Ding et al.'s recent study from Wuhan, China to investigate the relationship between COVID-19 disease and ovarian function in reproductive-aged women changes our treatment perspective [20]. Female COVID-19 patients of reproductive age were recruited between January 28 and March 8, 2020 from Tongji Hospital in Wuhan. Ovarian injury, including 
declined ovarian reserve and reproductive endocrine disorder, was observed in women with COVID-19 [20]. Ding et al. strongly suggest that more attention should be paid to ovarian function under this pandemic, especially regarding reproductive-aged women [20].

COVID-19 contains major structural proteins and one among them, the S protein can promote fusion of the viral and cellular membranes and facilitate the entry of coronavirus into the host cells [21]. Basigin (BSG) is one of the most important receptors for COVID-19 that mediates its entry into host cells [22]. Basigin has an important role in male and female reproduction. Basigin is expressed in the uterus and is needed for successful implantation. Therefore, any disruption or inhibition of Basigin causes impaired embryo implantation. Mahdian et al. recommended that infected couples must not attempt to procreate until their treatment is complete [22].

\section{Implications of COVID-19 in an IVF Labs}

Scientists have quickly related to good tissue practices in vitro fertilization and a rethink is on about encouraging biopsies and focusing on safe vitrification protocols keeping in mind that ova, sperm, and embryos could be possible vectors for disease transmission with the limited research on the SARS-CoV-2 virus. Over the last decade, improvements in cryosurvival and improved live birth rates have been associated with zona pellucida breaching protocols such as blastocyst collapsing and Day 5 biopsies [23]. In contemporary IVF lab practice, embryos are no longer protected by an intact zona pellucida when vitrified and in cryostorage. Today the trend is to always use high security storage containers which are resilient to potential cross-contamination and reliable for sperm freezing and embryo vitrification [23].

Studies in larger cohorts of currently infected men are warranted to confirm the presence of risks for male gametes that are destined either for cryopreservation in liquid nitrogen or for assisted reproduction techniques [24].

\section{Suggested Guidelines for IVF Physicians}

The COVID-19 pandemic has significantly increased mortality globally, with the number of infected cases increasing exponentially across continents. One of the main poor prognostic factors is the development of coagulopathy. It is well known that medically assisted reproduction (MAR) confers a risk of thromboembolic complications. In this pandemic, any risk of ovarian hyperstimulation should be avoided. Gonadotrophin-releasing hormone agonist triggering should be mandatory in all high-responder patients and/or those with COVID-19 infection [25]. In all patients, the treatment cycle should be segmented. Fabreques \& Penarrubia suggested the use of prophylactic low molecular weight heparin not only in those cases in which oocyte retrieval has been performed, but also in those in which cancellation has been decided [25]. They also added that endometrial preparation for frozen-thawed embryo transfers should use the transdermal route in order to minimize the higher thrombotic risk associated with the oral route [25].

With a lacuna of knowledge regarding SARS-CoV-2 pathogenesis during pregnancy, the pandemic calls for caution and all professional assisted reproduction governing bodies generally recommend postponing embryo transfers of current cycles and no initiation of new cycles, with rare exceptions. We must be alert to new evidence, which can change these recommendations at any time, in order to adjust the management of medically assisted reproductive treatments.

The Italian Society of Fertility and Sterility and Reproductive Medicine (SIFES-MR) put out an ART priorities official statement for all IVF labs for this pandemic [26]. They stressed that time to egg collection and drop-out rates are critical parameters for scheduling treatments once the curve of infections has peaked and plateaued in each country. In order to reduce the values for these two parameters, infertile patients now require even more support from their IVF team: urgent oocyte collection for oncology patients must be guaranteed, and oocyte retrievals for women with advanced maternal age and/or reduced ovarian reserve cannot be postponed indefinitely [26].

The China virus pandemic itself and the global recommendation by National \& International ART Societies to stop or postpone all medically assisted reproduction (MAR) programs generated severe psychological distress levels and depressive episodes in infertile couples. The psychological impact of COVID-19 pandemic in infertility patients should not be underestimated, and a psychiatric support should be strongly suggested to all vulnerable couples [27].

\section{COVID Vaccines \& Fertility}

Orveito et al. set up a study to assess the influence of mRNA SARS-CoV-2 vaccine on IVF treatments [28]. All couples undergoing consecutive ovarian stimulation cycles for IVF before and after receiving mRNA SARS-CoV-2 vaccine were recruited. The stimulation characteristics and embryological variables of these couples undergoing IVF treatments after receiving mRNA SARS-CoV-2 vaccine were assessed and compared to their IVF cycles prior to vaccination. mRNA SARS-CoV-2 vaccine did not affect patients' performance or ovarian reserve in their immediate subsequent IVF cycle [28].

In a very recent study of sperm parameters before and after 2 doses of a COVID-19 mRNA vaccine, there were 
no significant decreases in any sperm parameter among this small cohort of healthy men [4]. Because the vaccines contain mRNA and not the live virus, it is unlikely that the vaccine would affect sperm parameters.

\section{Current Understanding of COVID-19 in Pregnancy}

Based on most recent epidemiologic data on COVID-19 and pregnancy, there is no evidence to suggest increased risk for mothers or fetuses [8,29]. The course of disease after infection with SARS-CoV-2 in pregnancy does not differ from that in other young adults. Moreover, recent evidence suggests no association of vertical transmission and fetal malformations, and the management of pregnant patients should be individualized based on obstetrical indications and maternal/fetal health status [8, 29].

\section{Recent Advances}

Postmortem examination of the testes from 12 COVID-19 patients was performed using light and electron microscopy, and immunohistochemistry for lymphocytic and histiocytic markers. Reverse transcription-polymerase chain reaction (RT-PCR) was used to detect the virus in testicular tissue [12]. Testes from COVID-19 patients exhibited significant seminiferous tubular injury, reduced Leydig cells, and mild lymphocytic inflammation. Yang et al. found no evidence of SARS-CoV-2 virus in the testes in the majority (90\%) of the cases by RT-PCR, and in none by electron microscopy [12]. These findings can help physicians impart evidence-based guidance for sperm donation even in post-COVID individuals and outline clinical strategies to mitigate the risk of testicular injury during the COVID-19 disease course [12].

\section{Conclusion}

There is a hypothesis that testicular damage and subsequent infertility may result following COVID-19 infection, and the possibility of sexual transmission, as SARSCoV-2, has been identified in the semen of infected patients [30]. However, the available data and study findings are recent, based on small sample sizes, and present conflicting information. Currently, there is not enough evidence to support the need for asymptomatic couples to avoid intercourse to protect against virus transmission.

The current China virus pandemic has focused the attention of health-care providers away from non-lifethreatening diseases, including infertility. Infertility does not jeopardize the physical survival of infertile couples, but it does jeopardize the future quality of life. Infertility is multi-factorial, some of which are age-dependent, and their effects may become irreversible if correct treatment is not taken in time to prevent irreversible childlessness. Tesarik suggested that each case of infertility should be evaluated comprehensively to establish its position of priority [31]. Medically assisted reproduction (MAR) makes it possible to separate fertilization and pregnancy in the reproductive timeline. Although pregnant women infected with COVID-19 may have an increased risk of adverse neonatal outcomes, gametes do not transmit SARS-CoV-2. Going ahead with segmented IVF without delay, freezing the generated embryos and pushing back the embryo transfer until after the pandemic appears to be the best strategy at present.

An international group of researchers have proposed a prognostic-stratification of more vulnerable infertility cases in order to plan a progressive restart of worldwide fertility treatments. At a time when preventing complications and limiting burdens for national health systems represent relevant issues, their guidelines might help government authorities and IVF providers to identify patients who should be prioritized for the continuation of fertility care in a safe environment [32].

Unfortunately, medically assisted procreation will never be the same after this tragic China virus pandemic.

\section{References}

1. WHO - World Health Organization. WHO Coronavirus Disease (COVID-19) Dashboard. 2020a Available at: https:// covid19. who.int. Accessed on: July 27, 2021.

2. Pan F, Xiao X, Guo J, Song Y, Li H, Patel DP, Spivak AM, Alukal JP, Zhang X, Xiong C, Li PS, Hotaling JM. No Evi- dence of SARS-CoV-2 in Semen of Males Recovering from COVID-19. Fertil Steril. 2020. https://doi.org/10.1016/j.fertnstert.2020.04. 024.

3. Eisenberg ML. Coronavirus Disease 2019 (COVID-19) and Men's Reproductive Health. Fertil Steril. 2020. https://doi.org/ 10.1016/j.fertnstert.2020.04.039.

4. Gonzalez DC, Nassau DE, Khodamoradi K, Ibrahim E, Blachman-Braun R, Ory J, Ramasamy R. Sperm parameters before and after COVID-19 mRNA vaccination (Letters). JAMA. 2021;326(3):273-4.

5. Morris RS. SARS-CoV-2 spike protein seropositivity from vaccination or infection does not cause sterility. F S Rep. 2021. https:// doi.org/10.1016/j.xfre.2021.05.010.

6. ASRM - American Society for Reproductive Medicine COVID Task Force. patient management and clinical recommendations during the coronavirus (COVID-19) pandemic. UPDATE \#4. 2020 Available at: https://www.asrm.org/globalassets/asrm/asrm-content/news-and-publications/ covid-19/covidtaskforceupdate4.pdf

7. Lu-Culligan A., Iwasaki A. The false rumors about vaccines that are scaring women. The New York Times. https://www.nytimes. com/2021/01/26/opinion/covid-vaccine-rumors.html 
8. Male V. Are COVID-19 vaccines safe in pregnancy? Nat Rev Immunol. 2021. https://doi.org/10.1038/s41577-021-00525-y.

9. News, HaM. Head of Pfizer research: covid vaccine is female sterilization. Available at: https://archive.is/9EULk. Accessed January 6, 2020.

10. Kloc M, Uosef A, Kubiak JZ, Ghobrial RM. Exaptation of retroviral syncytin for development of syncytialized placenta, its limited homology to the SARS-CoV-2 spike protein and arguments against disturbing narrative in the context of COVID-19 vaccination. Biology (Basel). 2021;10(3):238.

11. Baden LR, El Sahly HM, Essink B, Kotloff K, Frey S, Novak R. Efficacy and safety of the mRNA-1273 SARS-CoV-2 vaccine. N Engl J Med. 2021;384:403-16.

12. Yang M, Chen S, Huang B, Zhong JM, Su H, Chen YJ, Cao Q, Ma L, He J, Li XF, Li X, Zhou JJ, Fan J, Luo DJ, Chang XN, Arkun K, Zhou M, Nie X. Pathological findings in the testes of COVID-19 patients: clinical implications. Eur Urol Focus. 2020;6(5):1124-9.

13. Pascolo L, Zito G, Zupin L, Luppi S, Giolo E, Martinelli M, De Rocco D, Crovella S, Ricci G. Renin Angiotensin System, COVID-19 and Male Fertility: Any Risk for Conceiving? Microorganisms. 2020. https://doi.org/10.3390/microorganisms8 101492.

14. Vishvkarma R, Rajender S. Could SARS-CoV-2 affect male fertility. Andrologia. 2020;52(9):e13712.

15. Younis JS, Abassi Z, Skorecki K. Is there an impact of the COVID-19 pandemic on male fertility? The ACE2 connection. Am J Physiol Endocrinol Metab. 2020. https://doi.org/10.1152/ ajpendo.00183.2020.

16. Seymen CM. The other side of COVID-19 pandemic: Effects on male fertility. J Med Virol. 2021;93(3):1396-402.

17. Shen Q, Xiao X, Aierken A, Liao M, Hua J. The ACE2 expression in Sertoli cells and germ cells may cause male reproductive disorder after SARS-CoV-2 infection. 2020 Available at: https:// osf.io/fs5hd/ DOI: 10.31219/osf.io/fs5hd.

18. Illiano E, Trama F, Costantini E. Could COVID-19 have an impact on male fertility? Andrologia. 2020;52(6):e13654.

19. Li K, Chen G, Hou H, Liao Q, Chen J, Bai H, Lee S, Wang C, Li $\mathrm{H}$, Cheng L, Ai J. Analysis of sex hormones and menstruation in COVID-19 women of child-bearing age. Reprod Biomed. 2021. https://doi.org/10.1016/j.rbmo.2020.09.020.

20. Ding T, Wang T, Zhang J, Cui P, Chen Z, Zhou S, Yuan S, Ma W, Zhang M, Rong Y, Chang J, Miao X, Ma X, Wang S. Analysis of ovarian injury associated with covid-19 disease in reproductiveaged women in Wuhan, China: an observational study. Front Med (Lausanne). 2021. https://doi.org/10.3389/fmed.2021.635255.

21. Weisblum Y, Schmidt F, Zhang F, Da Silva J, Poston D, Lorenzi JC, Muecksch F, Rutkowska M, Hoffmann HH, Michailidis E, Gaebler C, Agudelo M, Cho A, Wang Z, Gazumyan A, Cipolla M, Luchsinger L, Hillyer CD, Caskey M, Robbiani DF, Rice CM, Nussenzweig MC, Hatziioannou T, Bieniasz PD. Escape from neutralizing antibodies by SARS-CoV-2 spike protein variants. Elife. 2020;9:e61312.

22. Mahdian S, Shahhoseini M, Moini A. COVID-19 Mediated by Basigin Can Affect Male and Female Fertility. Int J Fertil Steril. 2020;14(3):262-3.

23. Pomeroy KO, Schiewe MC. Cryopreservation and IVF in the time of Covid-19: what is the best good tissue practice (GTP). J Assist Reprod Genet. 2020;37(10):2393-8.

24. Corona G, Baldi E, Isidori AM, Paoli D, Pallotti F, De Santis L, Francavilla F, La Vignera S, Selice R, Caponecchia L, Pivonello R, Ferlin A, Foresta C, Jannini EA, Lenzi A, Maggi M, Lombardo F. SARS-CoV-2 infection, male fertility and sperm cryopreservation: a position statement of the Italian society of andrology and sexual medicine (SIAMS) (Società Italiana di Andrologia e Medicina della Sessualità). J Endocrinol Invest. 2020. https://doi. org/10.1007/s40618-020-01290-w.
25. Fabregues F, Peñarrubia J. Assisted reproduction and thromboembolic risk in the COVID-19 pandemic. Reprod Biomed Online. 2020;41(3):361-4.

26. Vaiarelli A, Bulletti C, Cimadomo D, Borini A, Alviggi C, Ajossa S, Anserini P, Gennarelli G, Guido M, Levi-Setti PE, Palagiano A, Palermo R, Savasi V, Pellicer A, Rienzi L, Ubaldi FM. COVID-19 and ART: the view of the Italian society of fertility and sterility and reproductive medicine. Reprod Biomed Online. 2020. https:// doi.org/10.1016/j.rbmo.2020.04.003.

27. Esposito V, Rania E, Lico D, Pedri S, Fiorenza A, Strati MF, Conforti A, Marrone V, Carosso A, Revelli A, Zullo F, Di Carlo C, Venturella R. Influence of COVID-19 pandemic on the psychological status of infertile couples. Eur J Obstet Gynecol Reprod Biol. 2020. https://doi.org/10.1016/j.ejogrb.2020.08.025.

28. Orvieto R, Noach-Hirsh M, Segev-Zahav A, Haas J, Nahum R, Aizer A. Does mRNA SARS-CoV-2 vaccine influence patients' performance during IVF-ET cycle? Reprod Biol Endocrinol. 2021. https://doi.org/10.1186/s12958-021-00757-6.

29. Wenling Y, Junchao Q, Xiao Z, Ouyang S. Pregnancy and COVID-19: management and challenges. Rev Inst Med Trop Sao Paulo. 2020. https://doi.org/10.1590/s1678-9946202062062.

30. Perry MJ, Arrington S, Neumann LM, Carrell D, Mores CN. It is currently unknown whether SARS-CoV-2 is viable in semen or whether COVID-19 damages spermatozoa. Andrology. 2021;9(1):30-2.

31. Tesarik J. After corona: there is life after the pandemic. Reprod Biomed Online. 2020. https://doi.org/10.1016/j.rbmo.2020.04. 002.

32. Alviggi C, Esteves SC, Orvieto R, Conforti A, La Marca A, Fischer R, Andersen CY, Bühler K, Sunkara SK, Polyzos NP, Strina I, Carbone L, Bento FC, Galliano D, Yarali H, Vuong LN, Grynberg M, Drakopoulos P, Xavier P, Llacer J, Neuspiller F, Horton M, Roque M, Papanikolaou E, Banker M, Dahan MH, Foong S, Tournaye H, Blockeel C, Vaiarelli A, Humaidan P, Ubaldi FM. POSEIDON (Patient-Oriented Strategies Encompassing Individualized Oocyte Number) group COVID-19 and assisted reproductive technology services: repercussions for patients and proposal for individualized clinical management. Reprod Biol Endocrinol. 2020. https://doi.org/10.1186/s12958-020-00605-z.

Publisher's Note Springer Nature remains neutral with regard to jurisdictional claims in published maps and institutional affiliations.

\section{About the Author}

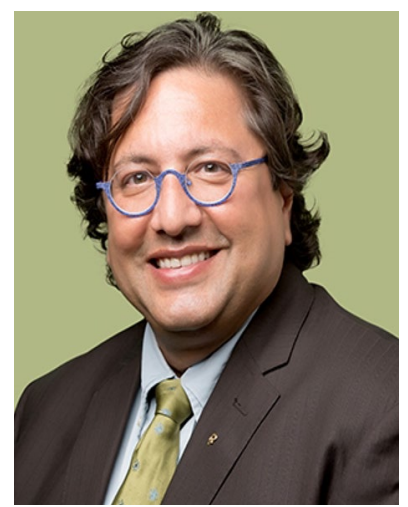

Gautam Allahbadia is a Consultant in Reproductive Endocrinology \& IVF at the Millennium Medical Center, DHCC \& Bourn Hall Fertility Clinic, Jumeirah, Dubai, UAE. He is the founder and Mentor of Rotunda-The Center for Human Reproduction, the world-renowned IVF Center at Parel, India. $\mathrm{He}$ is a noted world authority on Ultrasoundguided Embryo transfers and one of the pioneers in Third Party Reproduction in Southeast Asia. Dr. Allahbadia was responsible for India's first trans-ethnic surrogate pregnancy involving a Chinese couple's baby delivered by an 
unrelated Indian surrogate mother. Gautam N Allahbadia, MD is the Emeritus Editor of the Journal of Obstetrics \& Gynecology of India as well as the IVF Lite (Journal of Minimal Stimulation IVF). He cherishes over 150 peer-reviewed publications, 134 book chapters and 34 textbooks, the latest being a comprehensive text published by Springer International, entitled "Textbook of ART" in 2020, and is on the Editorial Board of several International Journals. Dr. Allahbadia was elected as the Vice President of the World Association of Reproductive Medicine (WARM), headquartered in Rome, and "Mumbai's Top Doc" for 2012 by a peer nomination process. He has a Consultant "A" Licensure with Dubai Health Authority (DHA) \& for four years he was an expert with DHA interviewing new doctors applying for the DHA License to practice in the UAE. You can read more about his work at www.gauta mallahbadia.com. 